\title{
Supplemental Material Identification of the Starting Group On the First PE Chain Produced by Phillips Catalyst
}

\author{
C.A. Cruz, M.M. Monwar, J. Barr and M.P. McDaniel*
}

\section{Percentage of active $\mathrm{Cr}$ :}

As noted in the main paper, almost no chain termination (vinyls) were observed in these experiments, which implies a quasi-living system. That is, each chain is still attached to its parent site, at the time of quenching. Upon hydrolysis with methanol, each active site leaves one polymer chain, and therefore counting the number of chains produced is equivalent to counting the active site population, or it at least it serves as a lower bound. In Tables 1 and 3 the number of chains produced per $\mathrm{Cr}$ is listed, and these numbers are large enough to suggest that, at least in some experiments, a relatively large fraction of the $\mathrm{Cr}$ was involved in the polymerization.

This is somewhat unexpected from many past studies where poisoning or $\mathrm{Cr}$ loading experiments, or various forms of spectroscopy, were used to estimate the number of active sites. Actually, these estimations vary widely, as they should, depending on the catalyst preparation and how the polymerization was done. Some of the numbers reported are quite small $(<1 \%)^{1}$ while others can be fairly large ${ }^{2,3}$. A summary of all these estimations can be found in ref [4].

One of the reasons why such estimations could be understated is that they usually implicitly assume that all sites have the same activity, that is, that a site is active or not active. Let us call this idea interpretation A. And the change in activity that is measured with poison or loading changes is really an average or extrapolation of some of the most active sites. To illustrate, let us choose an example where the catalyst and polymerization technique are very close to that used in the present study. In one study the catalyst activity was titrated with $\mathrm{CO}^{5}$ and in another study the poison used was diethyl sulfide ${ }^{6}$. The $\mathrm{CO}$ titration is shown below in Figure S1.

1 Myers, D.L.; Lundsford, J.H. Silica-supported Catalysts for Ethene Polymerization, J. Catal. 1985, 92, 260-271.

2 Garrone, E.; Ghiotti, G.; Morterra, C.; Zecchina, A. The Chemistry of Silica-Supported Chomium lons: Nitric Oxide Complexes and Their Interaction with $\mathrm{CO}$ and Pyridine. Zeitschrift fur Naturforsschung $B, 1987,42 \mathrm{~b}, 728-738$.

3 Vikulov, K.; Spoto, G.; Coluccia, S.; Zecchina, A., FTIR Investigation of Ethylene Coordination and Polymerization on Reduced Cr/SiO2 Catalyst, Catalysis Letters 1992, 16, 117-122.

4 McDaniel, M.P. A Review of the Phillips Supported Chromium Catalyst and Its Commercial Use for Ethylene Polymerization. Advances in Catalysis 2010, 53, 123-606 (Ed. B.C. Gates, H. Knoezinger, F.C. Jentoft, Academic Press, Elsevier).

5 McDaniel, M.P.; Martin, S.J. J. Phys. Chem. 1991, 95(8), 3289-3293.

6 Grayson, M.E.; McDaniel, M.P., J. Catal. 1991, 65, 139-144. 
Notice that $\mathrm{CO}$ becomes less and less effective as a poison as more of it is added. This is typical of many catalytic reactions and the explanation usually given is that the poison, or more accurately the active sites, are becoming less and less selective. Therefore, the active site population is usually obtained by extrapolation of the initial slope, which produces a low number, and which assumes that all sites have the same activity. This idea we called interpretation A. But another explanation, let us call it interpretation B, could also be advanced, namely, that the most active sites are killed first (most acidic), in which case the true active site population is actually much larger than that from interpretation A. And under interpretation B, sites are allowed to have different activities. Examination of the MW or MW distribution of the polymer does suggest that the first sites to be poisoned do produce different polymer from those killed later, and therefore not all sites are equal. Thus, In Figure S1 below and under interpretation B, greater than $25 \%$ of the Cr could be active, perhaps $50 \%$.

Figure S1 Poisoning of $\mathrm{Cr} /$ Silica-titania by Carbon Monoxide

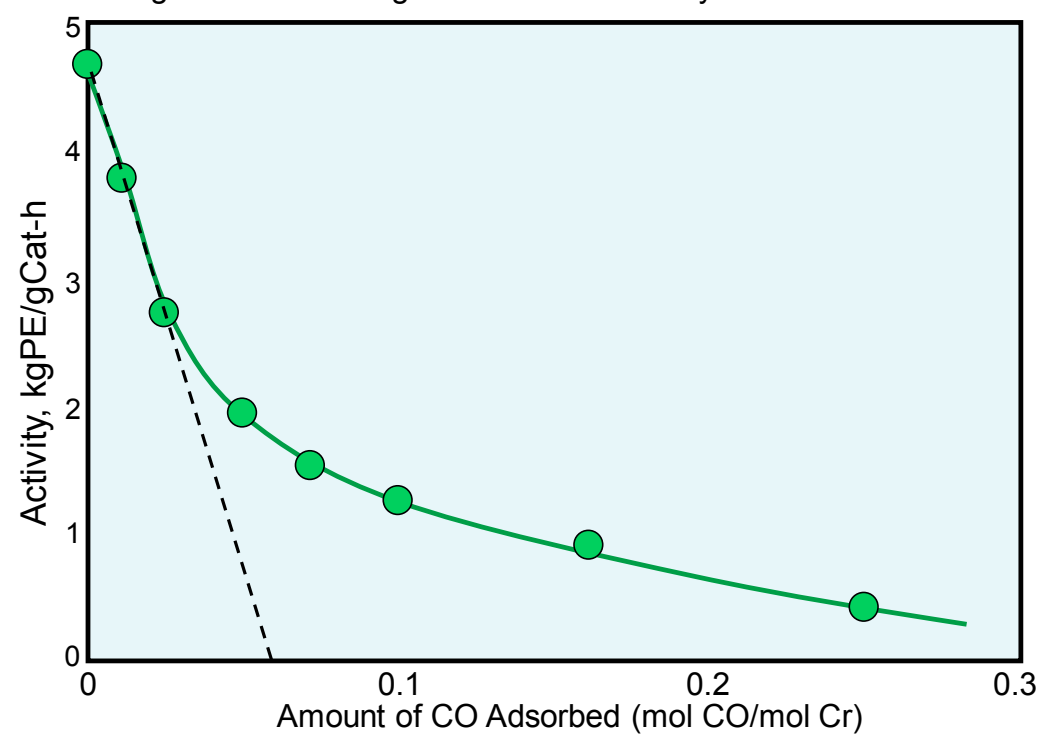

Now consider another well-used method of calculating the concentration of active sites, that is, by varying the $\mathrm{Cr}$ loading. Figure $\mathrm{S} 2$ shows an example of this method, which was introduced by Hogan, with ref [4] and [7] serving as examples. When expressed as activity per $\mathrm{Cr}$, the first increment of $\mathrm{Cr}$ to be added is by far the most active, although the activity of the whole catalyst is still quite low due to the small amount of $\mathrm{Cr}$ present. As more $\mathrm{Cr}$ is added, the average activity per $\mathrm{Cr}$ keeps dropping while the overall catalyst activity goes up. This trend is often explained as being due to the $\mathrm{Cr}$ being less and less efficiently used. That is, more of the $\mathrm{Cr}$ is adsorbed in an inactive form. So again we have interpretation $\mathrm{A}$. It assumes that all of the $\mathrm{Cr}$ has the same activity, and that $\mathrm{Cr}$ is either active or inactive. Finally, notice that the arrow in Figure S2 points to the conventional loading of $1 \% \mathrm{Cr}$. At this point, if one assumes that all of the active $\mathrm{Cr}$ has an activity equal to the first $\mathrm{Cr}$ added, then we calculate that only $8 \%$ of the total $\mathrm{Cr}$ is active at $1 \% \mathrm{Cr}$ loading. Again, this assumes that all of the $\mathrm{Cr}$ has the same activity.

7 Hogan, J.P. J. Polym. Sci. Part A-1, 1970, 8, 2637-2652, 


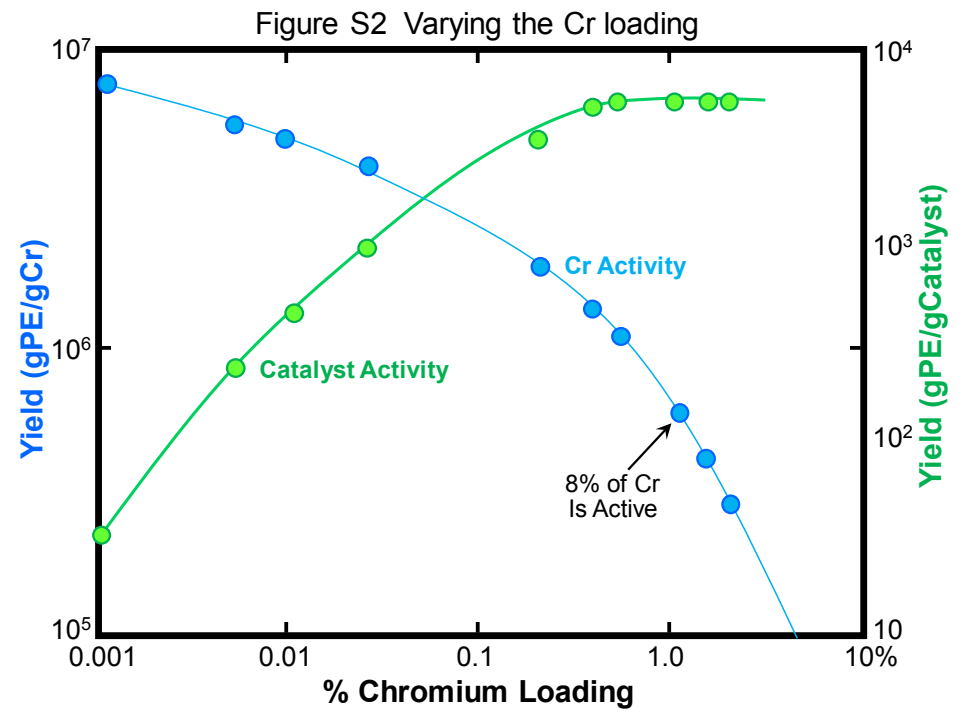

Again, this is from interpretation A. But another explanation can be applied to this chart too, interpretation B. As the other extreme, one could also assume that all of the $\mathrm{Cr}$ is active, and that the measured incremental activity is indeed the real activity of that increment of $\mathrm{Cr}$. It is not an average of active and inactive $\mathrm{Cr}$. This interpretation $\mathrm{B}$ gives a much higher participation of the $\mathrm{Cr}$, in which the activity varies considerably, but a relatively large fraction of the total $\mathrm{Cr}$ is active.

It is these two, quite different, interpretations of data that was alluded to in the main paper. Most published data uses a variant of interpretation A. But counting live chains, as was done in the present paper, gives a more direct measure of site concentration, without these assumptions or interpretations. This study seems to give relatively higher $\mathrm{Cr}$ participation numbers, perhaps more in line with a variant of interpretation B. At first, this seems to contradict earlier data, but what it is really contradicting is the interpretation A of earlier data. 


\section{NMR Spectra}

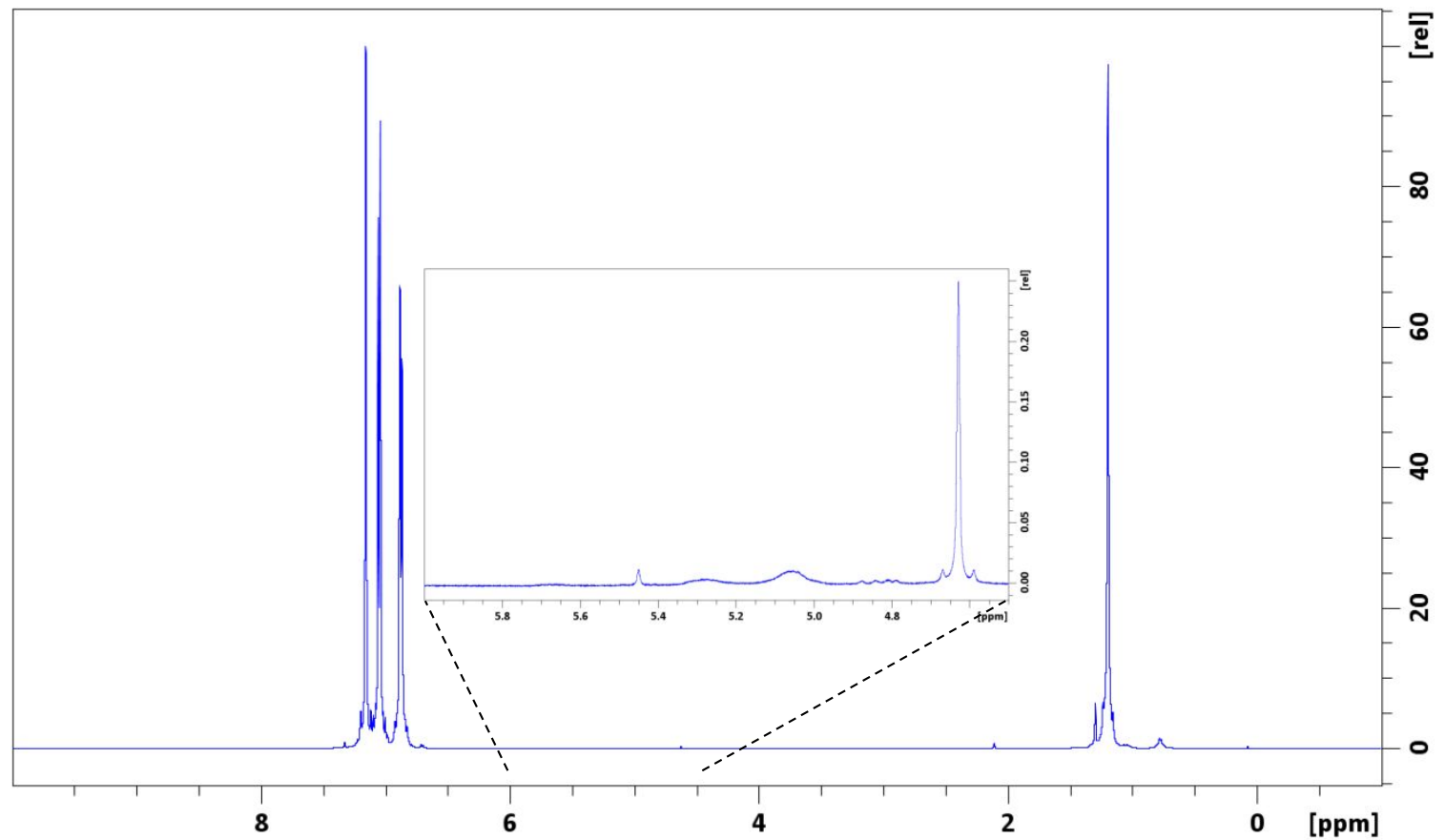

Figure S3: $500 \mathrm{MHz}{ }^{1} \mathrm{H}$ NMR spectrum of polyethylene (PE) sample 1 (Expt. 1). The expanded and zoomed olefinic region is shown in the inset.

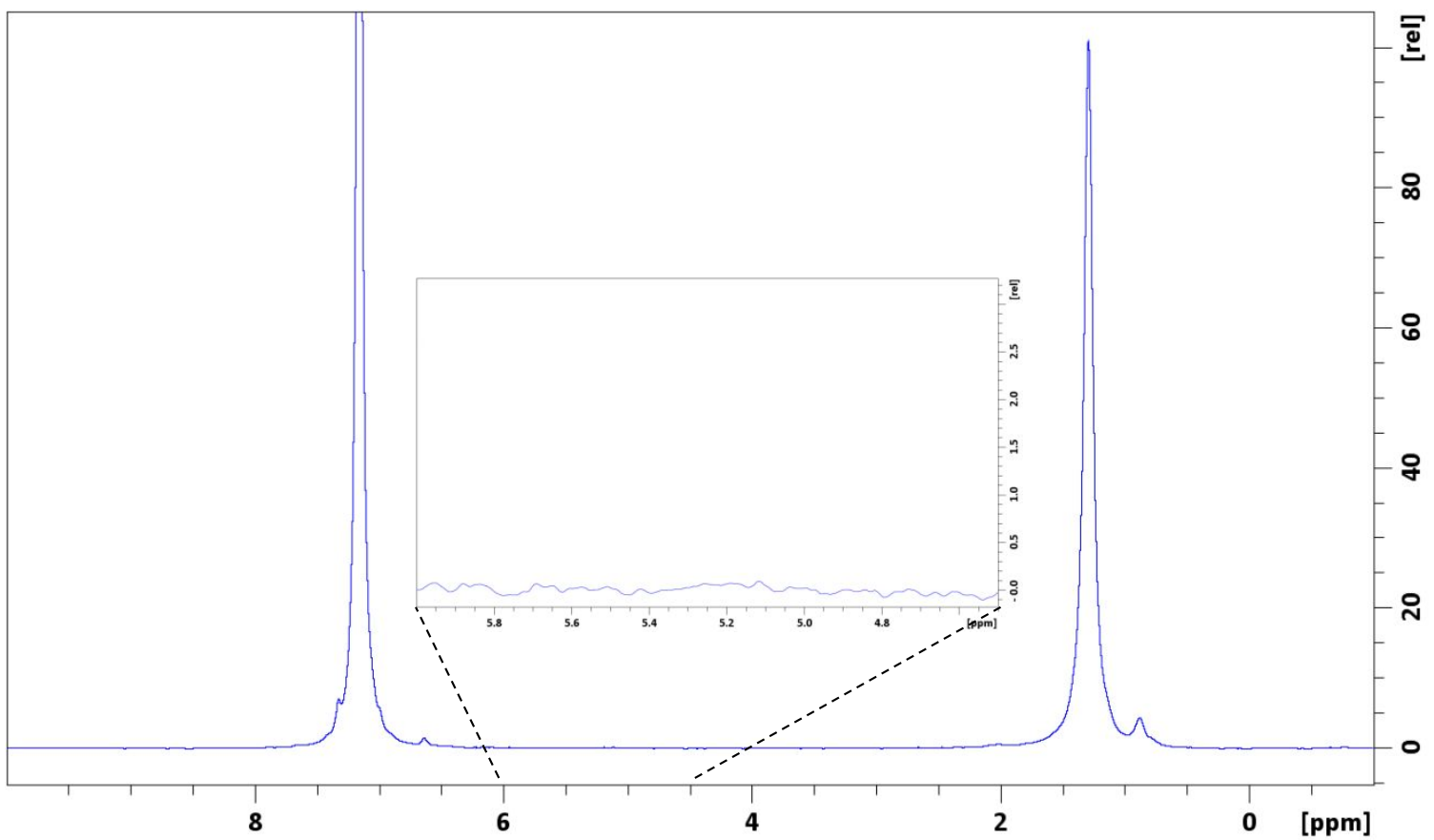

Figure S4: $76.7 \mathrm{MHz}{ }^{2} \mathrm{H}$ NMR spectrum of PE sample 1 (Expt. 1). The expanded and zoomed olefinic region is shown in the inset. 


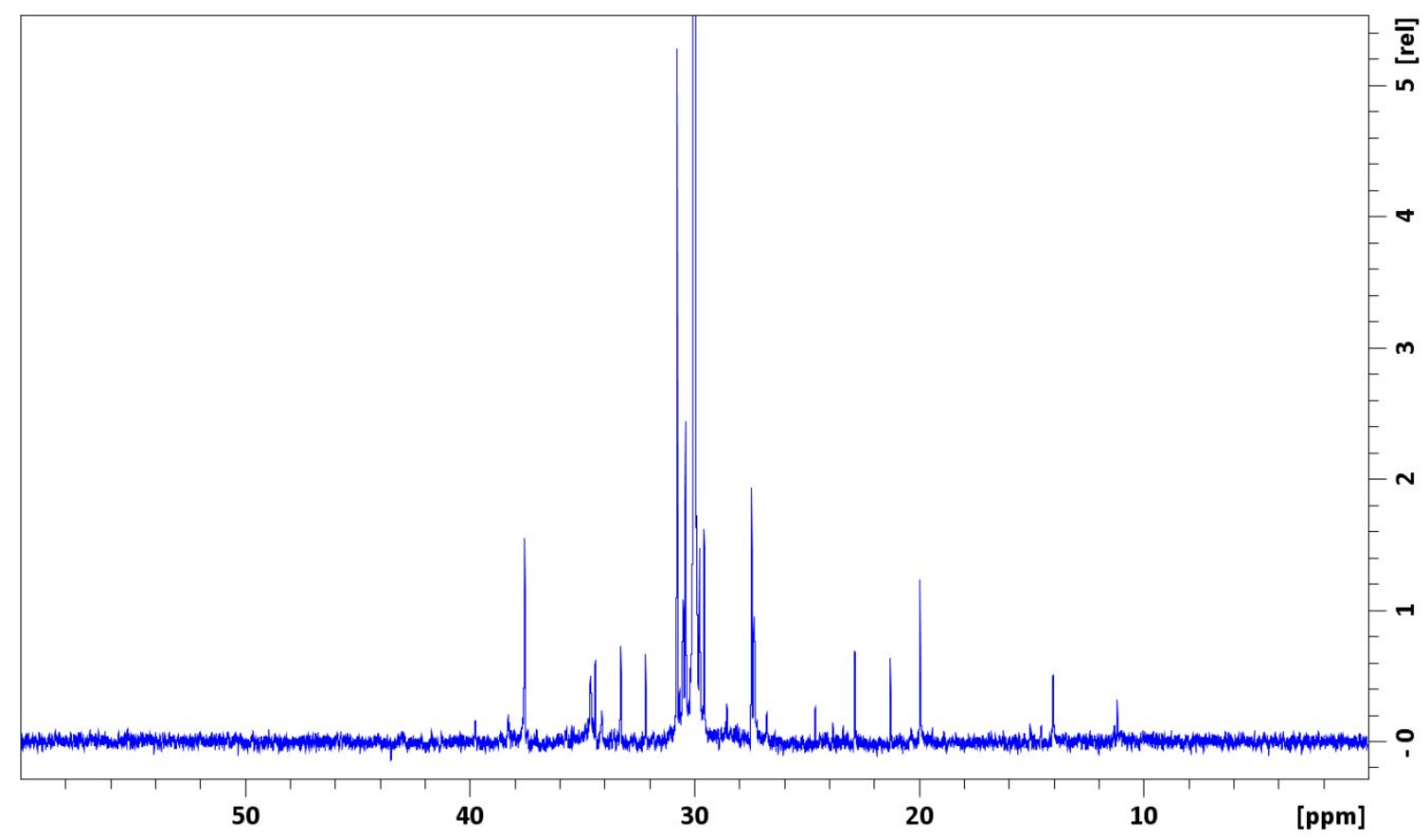

Figure S5: $0-60 \mathrm{ppm}$ region of $125.0 \mathrm{MHz}{ }^{13} \mathrm{C}$ NMR spectrum of PE sample 1 (Expt. 1). The spectrum is referenced with backbone PE peak $\left(\delta^{+} \delta^{+}\right)$at $30.0 \mathrm{ppm}$ and the relative intensity of the peak is set at 100 .

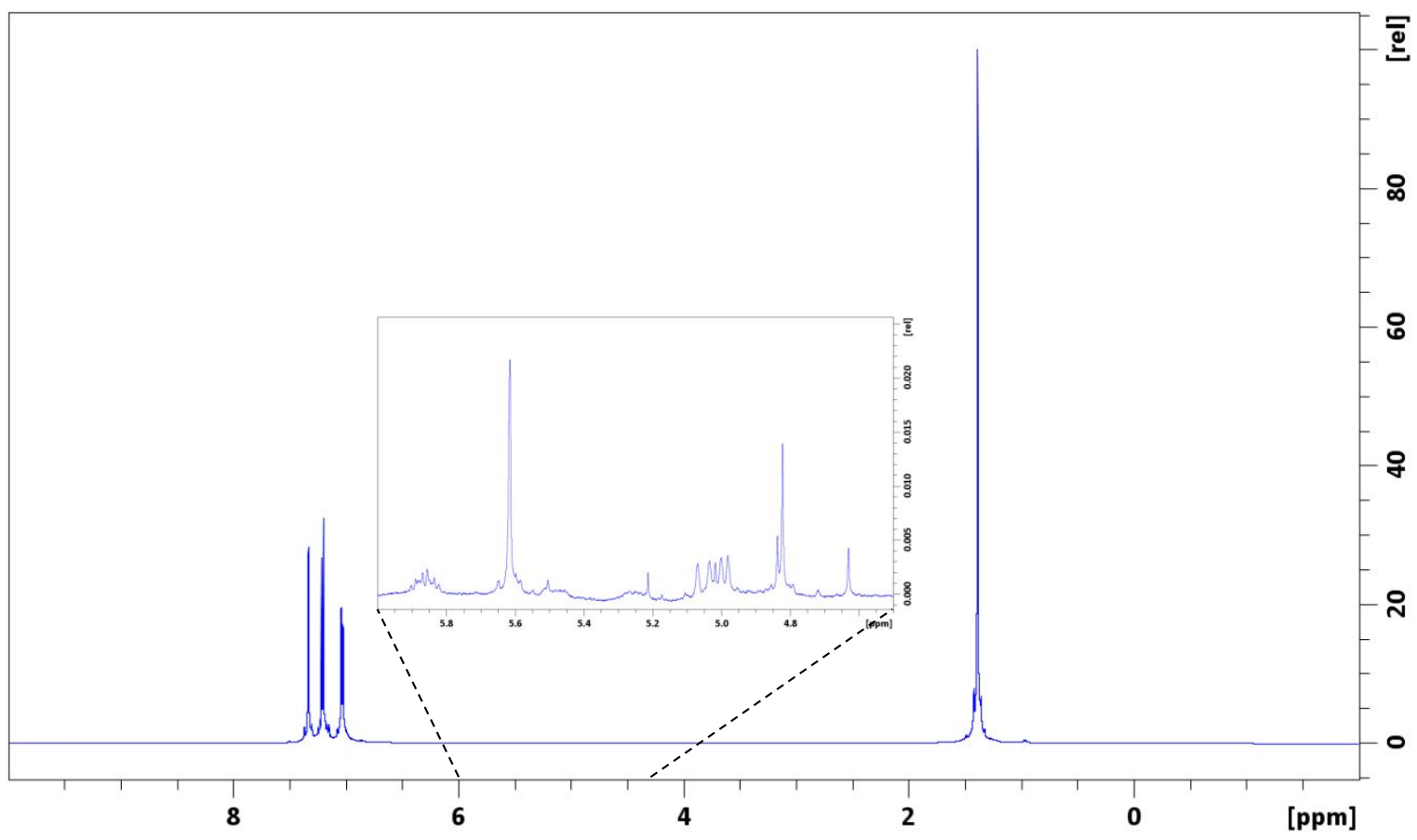

Figure S6: $500 \mathrm{MHz}{ }^{1} \mathrm{H}$ NMR spectrum of PE sample 2 (Expt. 2). The expanded and zoomed olefinic region is shown in the inset. 


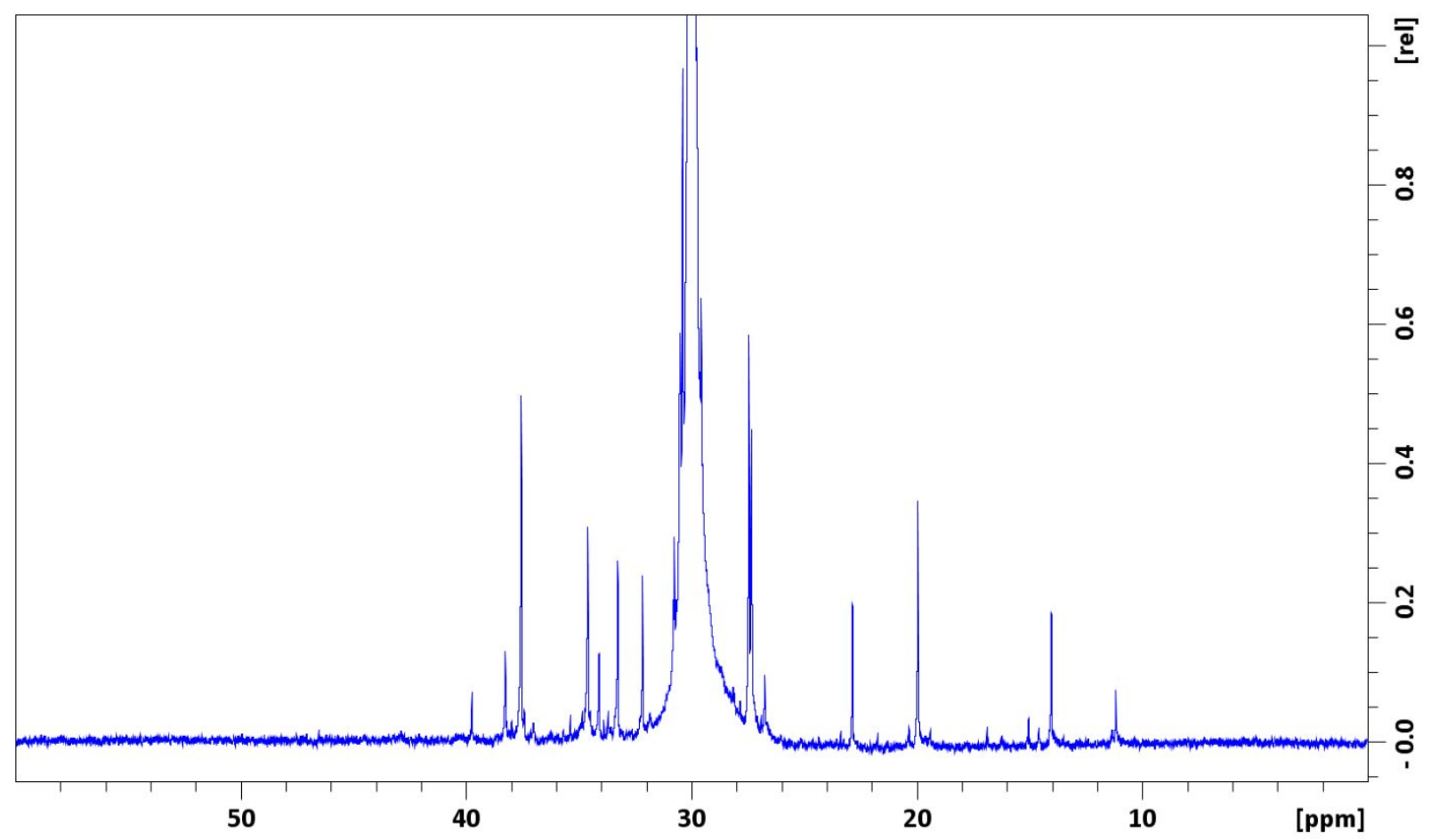

Figure S7: $0-60 \mathrm{ppm}$ region of $125.0 \mathrm{MHz}{ }^{13} \mathrm{C}$ NMR spectrum of PE sample 2 (Expt. 2). The spectrum is referenced with backbone PE peak $\left(\delta^{+} \delta^{+}\right)$at $30.0 \mathrm{ppm}$ and the relative intensity of the peak is set at 100 .

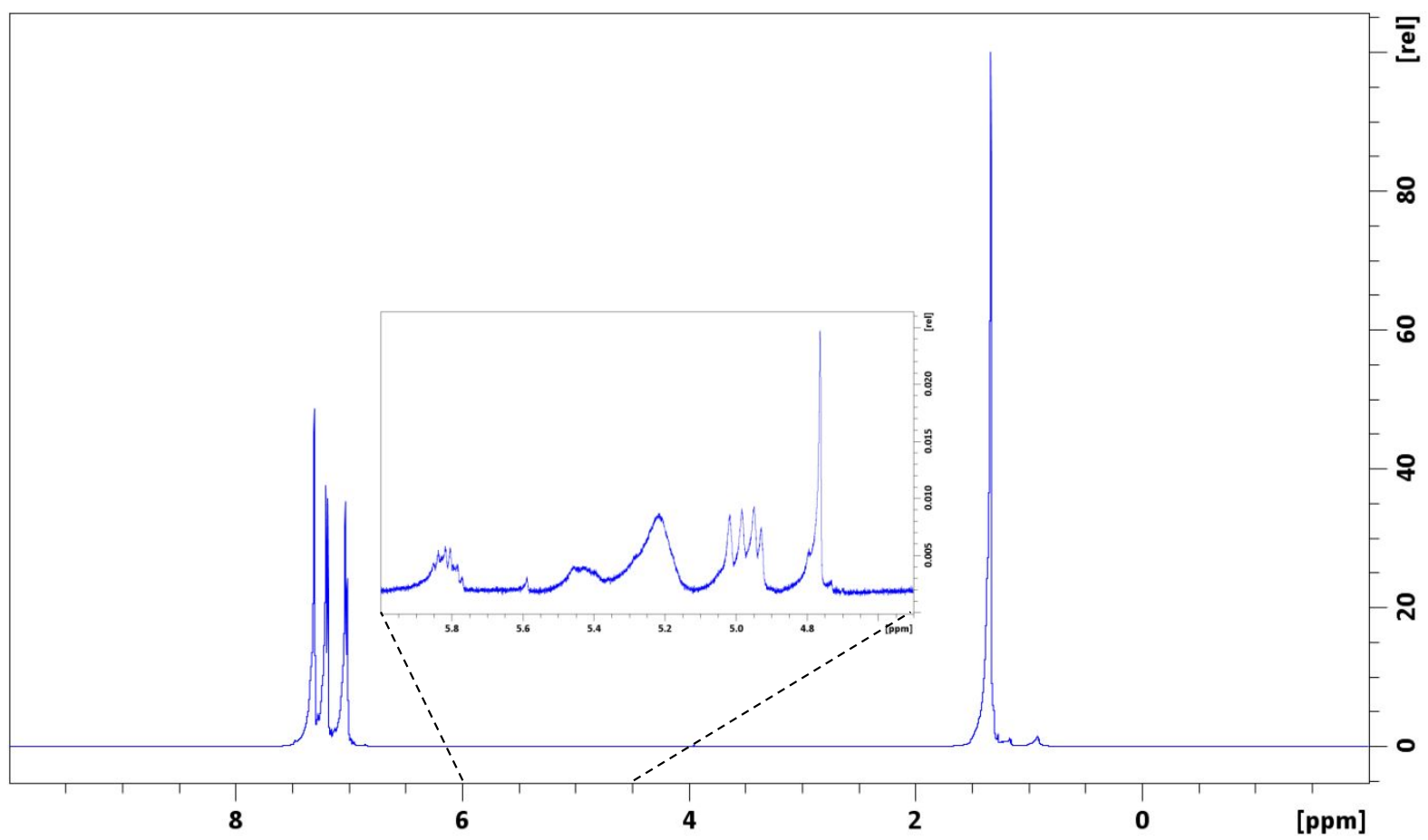

Figure S8: $500 \mathrm{MHz}{ }^{1} \mathrm{H}$ NMR spectrum of PE sample 3 (Expt. 3). The expanded and zoomed olefinic region is shown in the inset. 


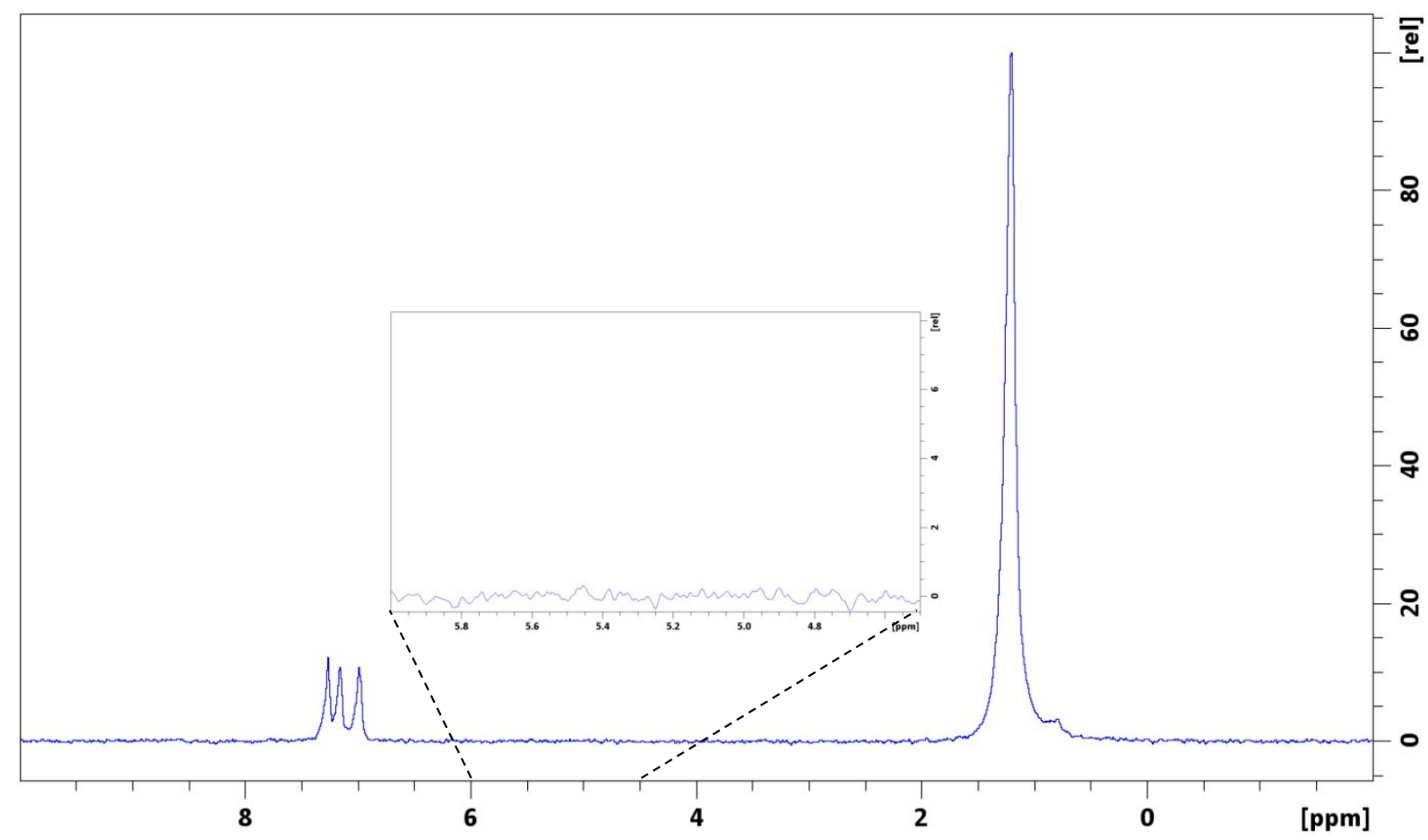

Figure S9: $76.7 \mathrm{MHz}{ }^{2} \mathrm{H}$ NMR spectrum of PE sample 3 (Expt. 3). The expanded and zoomed olefinic region is shown in the inset.

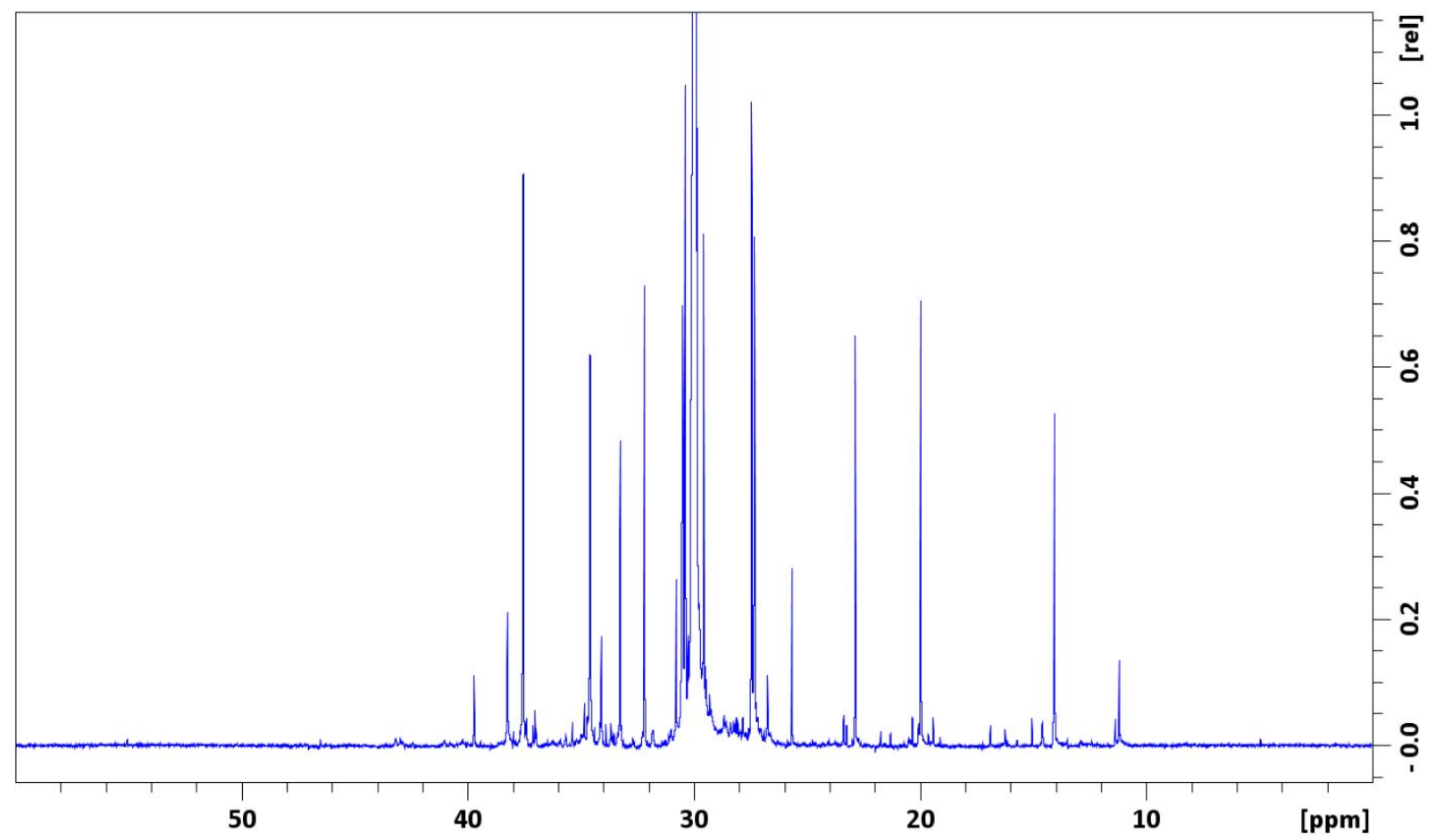

Figure S10: $0-60 \mathrm{ppm}$ region of $125.0 \mathrm{MHz}{ }^{13} \mathrm{C}$ NMR spectrum of PE sample 3 (Expt. 3). The spectrum is referenced with backbone PE peak $\left(\delta^{+} \delta^{+}\right)$at $30.0 \mathrm{ppm}$ and the relative intensity of the peak is set at 100 . 


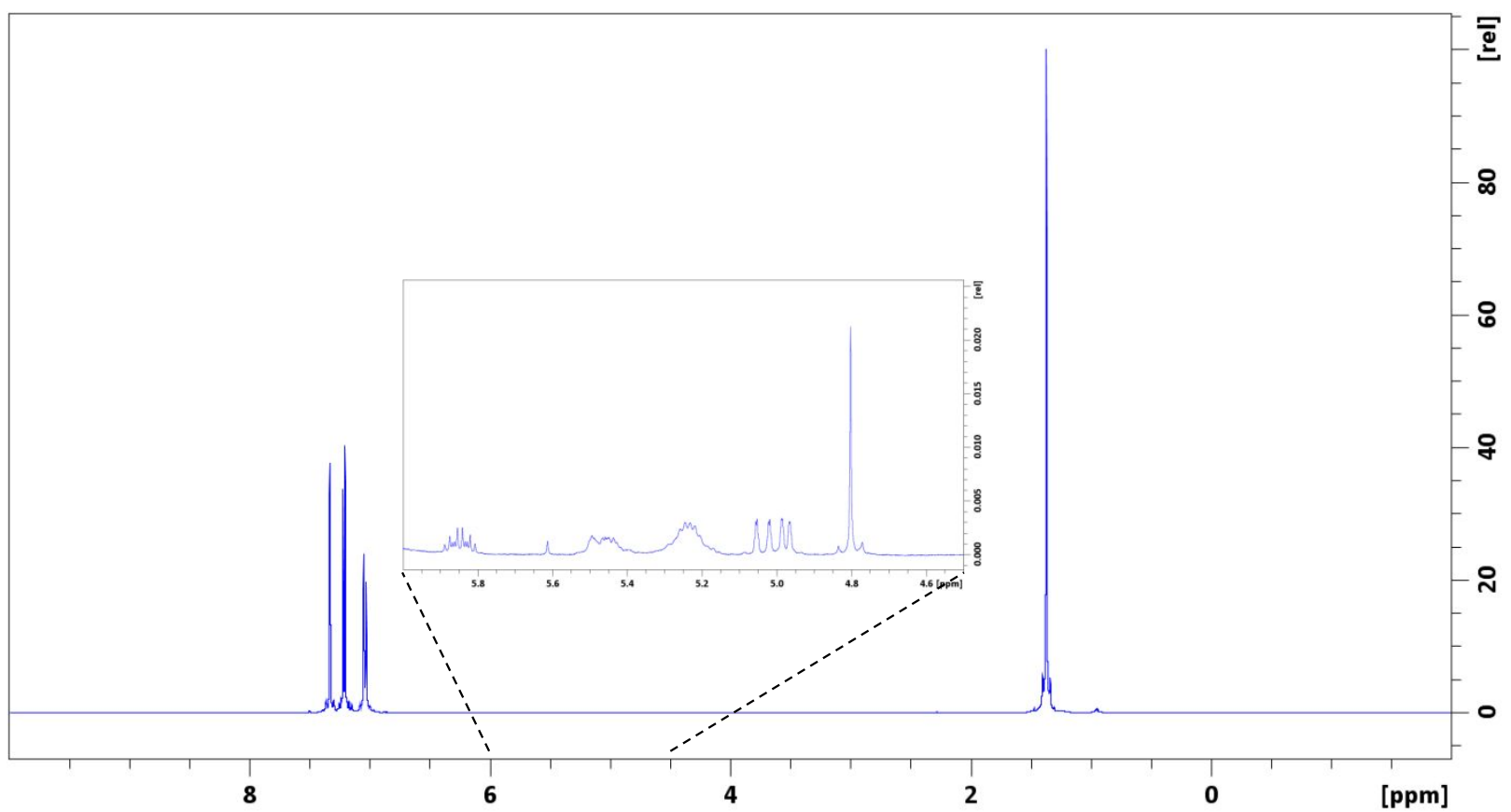

Figure S11: $500 \mathrm{MHz}{ }^{1} \mathrm{H}$ NMR spectrum of PE sample 4 (Expt. 4). The expanded and zoomed olefinic region is shown in the inset.

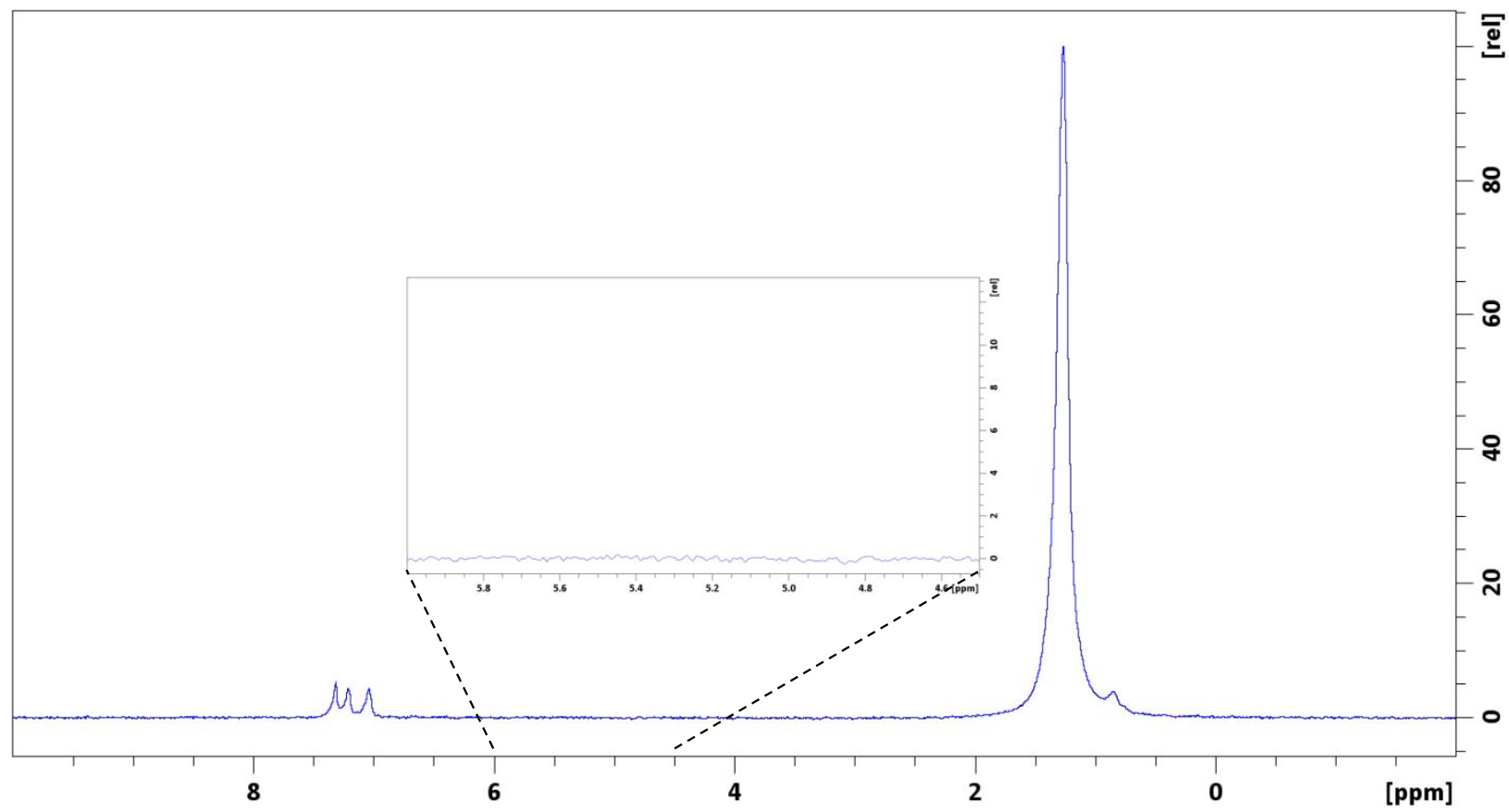

Figure S12: $76.7 \mathrm{MHz}{ }^{2} \mathrm{H}$ NMR spectrum of PE sample 4 (Expt. 4). The expanded and zoomed olefinic region is shown in the inset. 


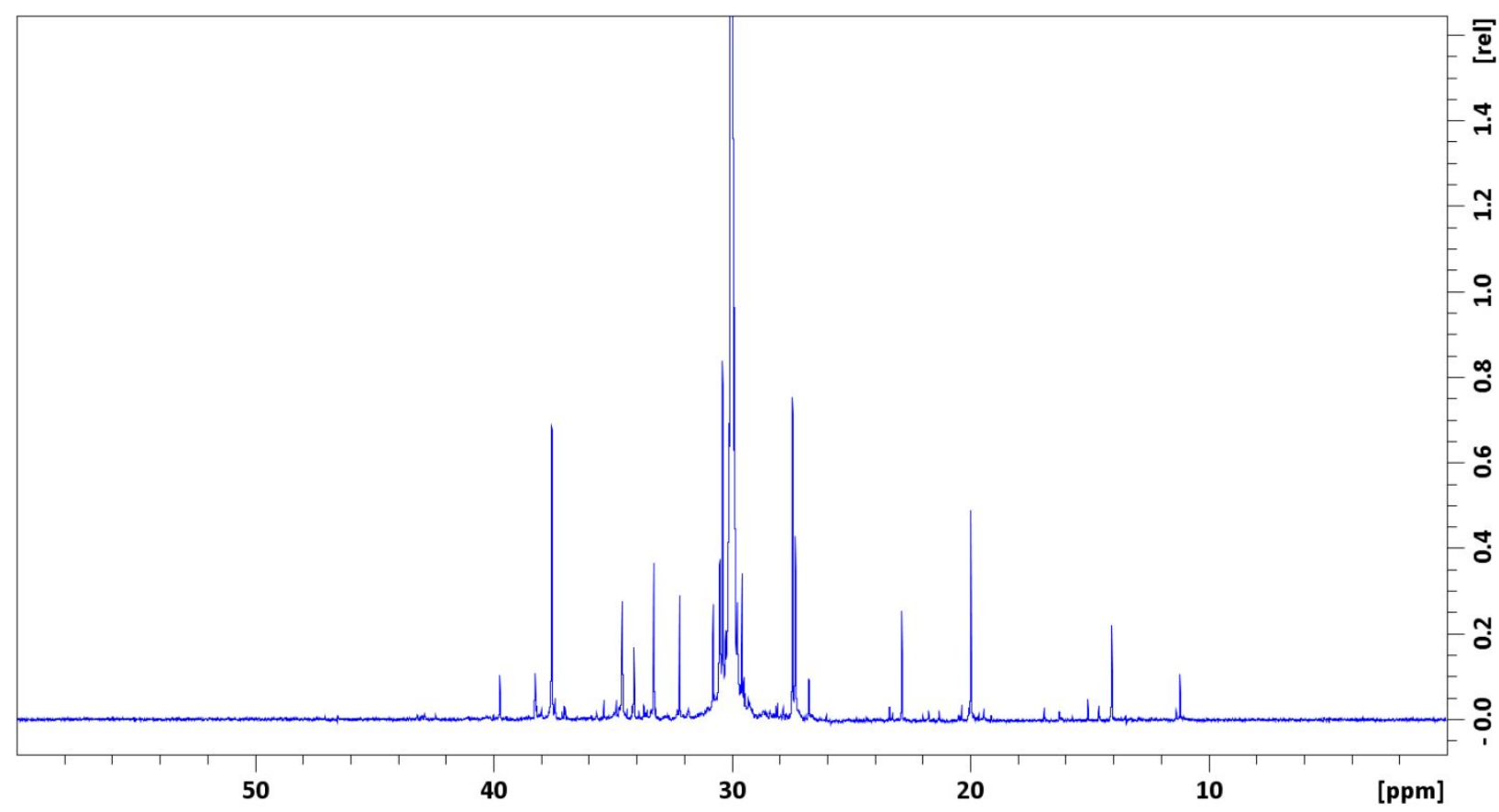

Figure S13: $0-60$ ppm region of $125.0 \mathrm{MHz}{ }^{13} \mathrm{C}$ NMR spectrum of PE sample 4 (Expt. 4). The spectrum is referenced with backbone PE peak $\left(\delta^{+} \delta^{+}\right)$at $30.0 \mathrm{ppm}$ and the relative intensity of the peak is set at 100 .

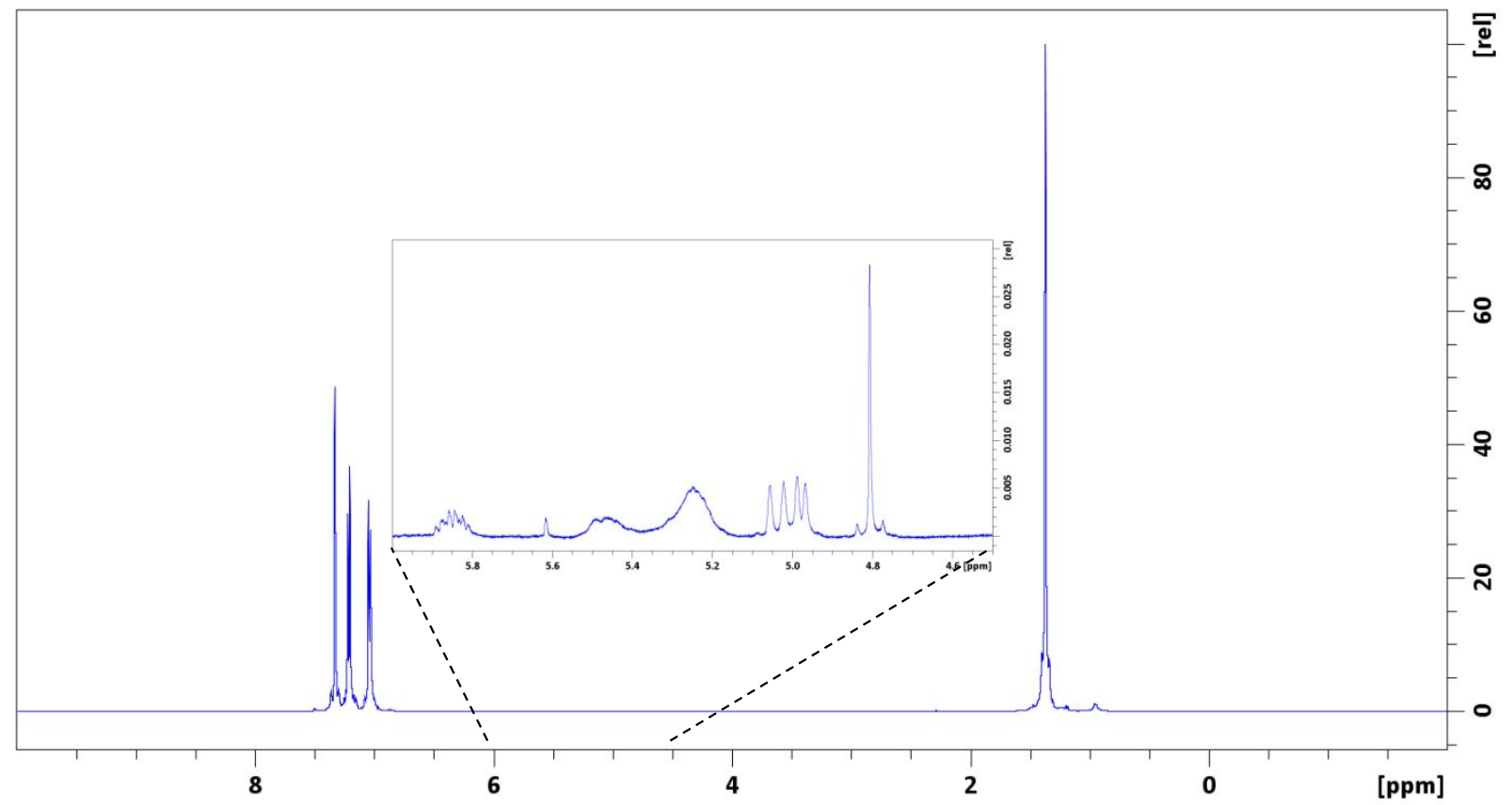

Figure S14: $500 \mathrm{MHz}{ }^{1} \mathrm{H}$ NMR spectrum of PE sample 5 (Expt. 5). The expanded and zoomed olefinic region is shown in the inset. 


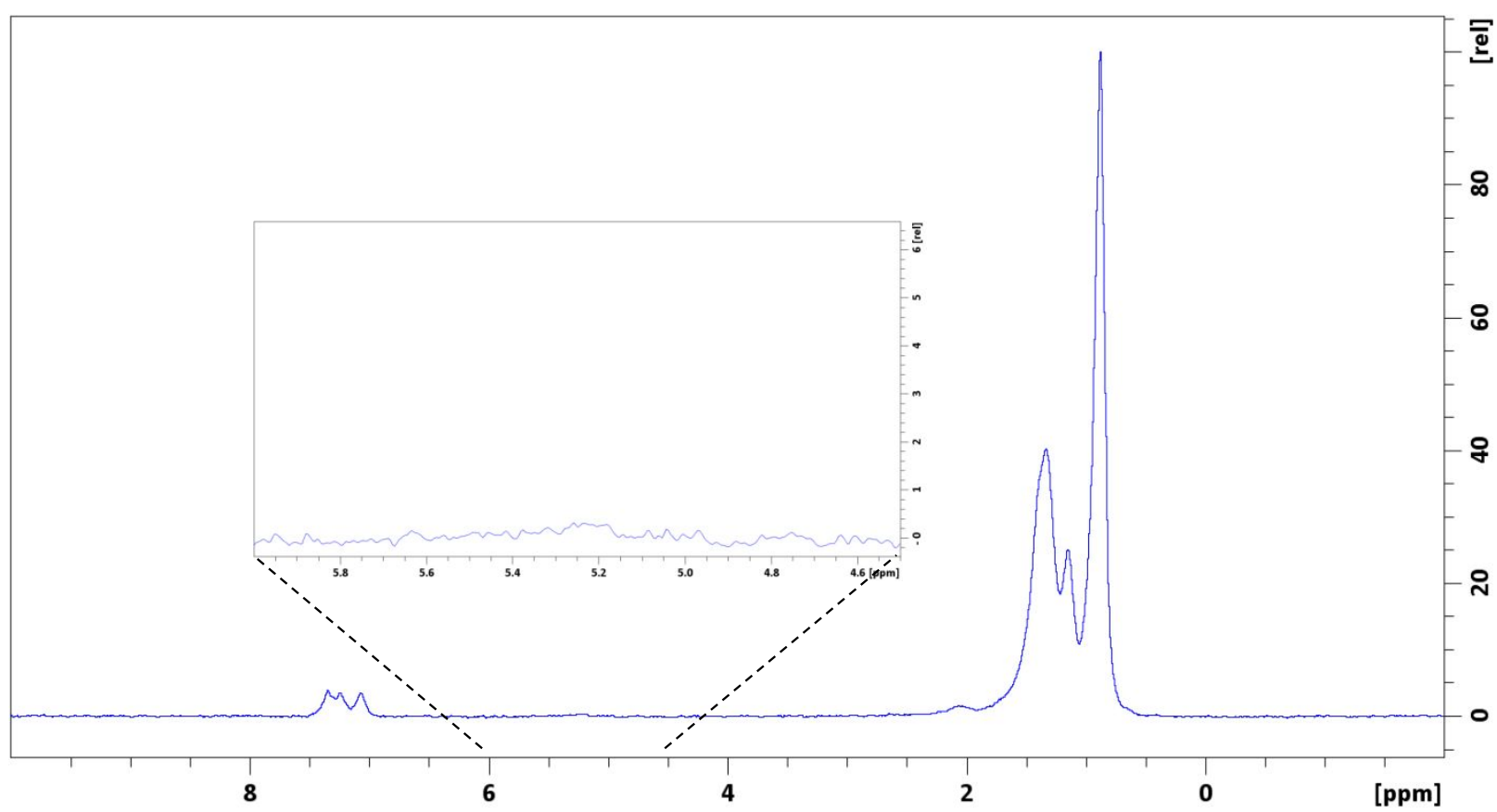

Figure S15: 76.7 MHz ${ }^{2} \mathrm{H}$ NMR spectrum of PE sample 5 (Expt. 5). The expanded and zoomed olefinic region is shown in the inset.

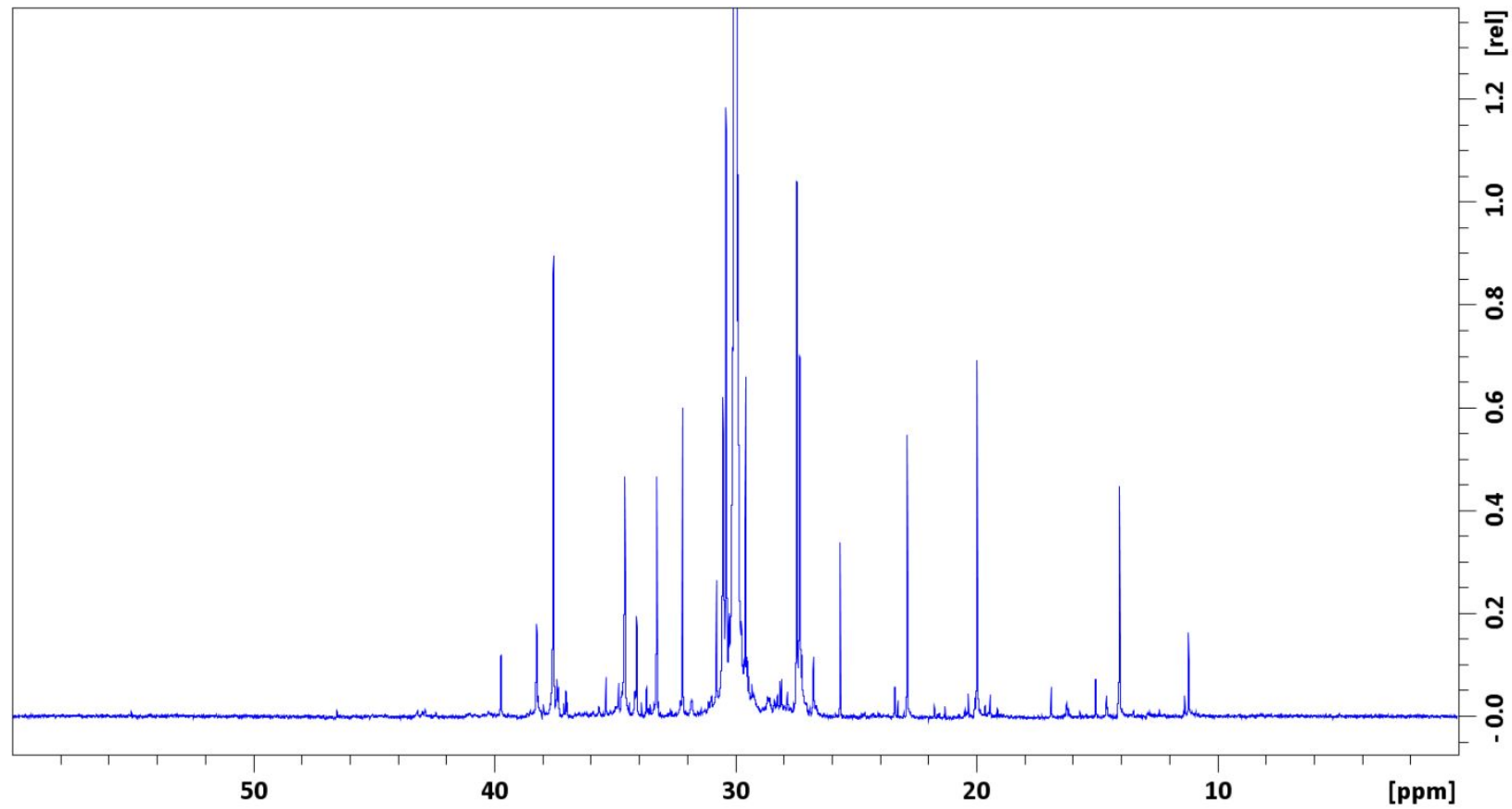

Figure S16: $0-60 \mathrm{ppm}$ region of $125.0 \mathrm{MHz}{ }^{13} \mathrm{C}$ NMR spectrum of PE sample 5 (Expt. 5). The spectrum is referenced with backbone PE peak $\left(\delta^{+} \delta^{+}\right)$at $30.0 \mathrm{ppm}$ and the relative intensity of the peak is set at 100 . 


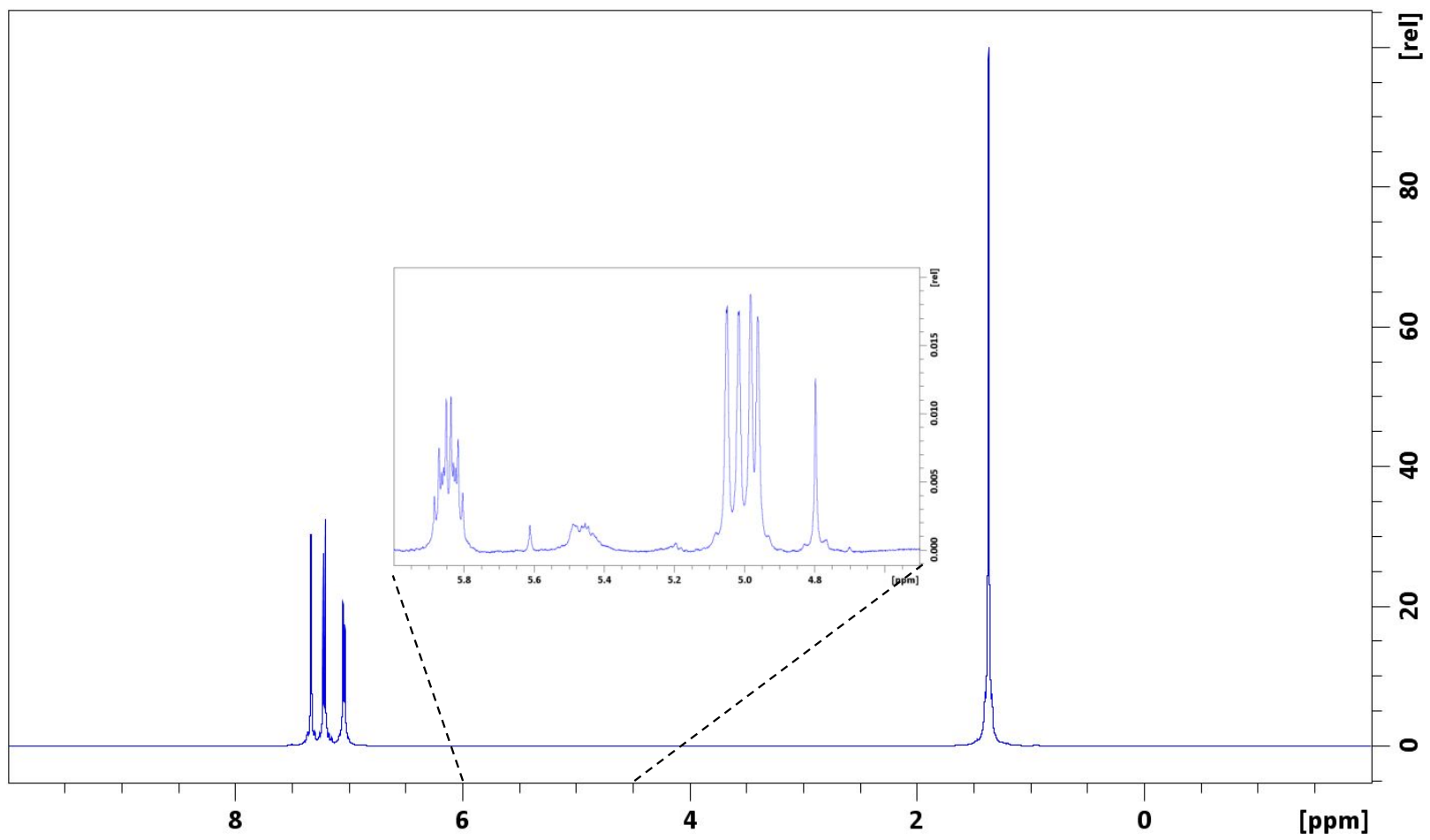

Figure S17: $500 \mathrm{MHz}{ }^{1} \mathrm{H}$ NMR spectrum of PE sample 6 (Expt. 6). The expanded and zoomed olefinic region is shown in the inset.

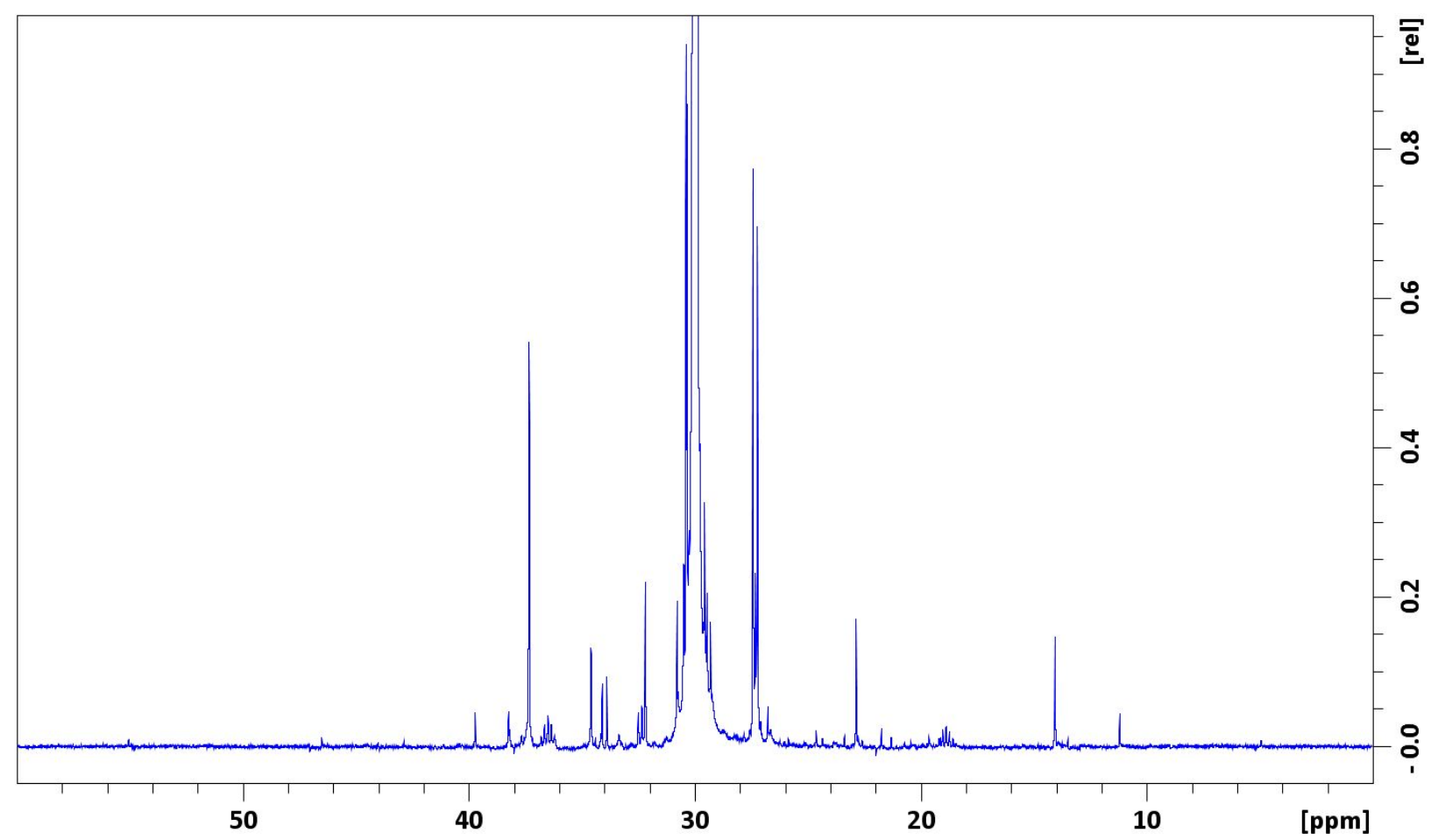

Figure S18: $0-60 \mathrm{ppm}$ region of $125.0 \mathrm{MHz}{ }^{13} \mathrm{C}$ NMR spectrum of PE sample 6 (Expt. 6). The spectrum is referenced with backbone PE peak $\left(\delta^{+} \delta^{+}\right)$at $30.0 \mathrm{ppm}$ and the relative intensity of the peak is set at 100 . 